\title{
Modified Origins of Cortical Projections to the Superior Colliculus in the Deaf: Dispersion of Auditory Efferents
}

\author{
일. Blake E. Butler, ${ }^{1,2,3}$ 이 Julia K. Sunstrum, ${ }^{4}$ and ${ }^{\circ}$ Stephen G. Lomber ${ }^{1,2,3,5}$ \\ ${ }^{1}$ Department of Psychology, ${ }^{2}$ Brain and Mind Institute, ${ }^{3}$ National Centre for Audiology, ${ }^{4}$ Psychology Undergraduate Program, and ${ }^{5}$ Department of \\ Physiology and Pharmacology, University of Western Ontario, London, Ontario N6A5C1, Canada
}

Following the loss of a sensory modality, such as deafness or blindness, crossmodal plasticity is commonly identified in regions of the cerebrum that normally process the deprived modality. It has been hypothesized that significant changes in the patterns of cortical afferent and efferent projections may underlie these functional crossmodal changes. However, studies of thalamocortical and corticocortical connections have refuted this hypothesis, instead revealing a profound resilience of cortical afferent projections following deafness and blindness. This report is the first study of cortical outputs following sensory deprivation, characterizing cortical projections to the superior colliculus in mature cats $(N=5,3$ female) with perinatal-onset deafness. The superior colliculus was exposed to a retrograde pathway tracer, and subsequently labeled cells throughout the cerebrum were identified and quantified. Overall, the percentage of cortical projections arising from auditory cortex was substantially increased, not decreased, in early-deaf cats compared with intact animals. Furthermore, the distribution of labeled cortical neurons was no longer localized to a particular cortical subregion of auditory cortex but dispersed across auditory cortical regions. Collectively, these results demonstrate that, although patterns of cortical afferents are stable following perinatal deafness, the patterns of cortical efferents to the superior colliculus are highly mutable.

Key words: auditory cortex; deafness; efferent; multisensory; plasticity; superior colliculus

Significance Statement

When a sense is lost, the remaining senses are functionally enhanced through compensatory crossmodal plasticity. In deafness, brain regions that normally process sound contribute to enhanced visual and somatosensory perception. We demonstrate that hearing loss alters connectivity between sensory cortex and the superior colliculus, a midbrain region that integrates sensory representations to guide orientation behavior. Contrasting expectation, the proportion of projections from auditory cortex increased in deaf animals compared with normal hearing, with a broad distribution across auditory fields. This is the first description of changes in cortical efferents following sensory loss and provides support for models predicting an inability to form a coherent, multisensory percept of the environment following periods of abnormal development.

\section{Introduction}

The superior colliculus (SC) is a midbrain structure that plays a central role in orienting toward environmental stimuli. Multisensory in nature, the SC maintains coregistered representations of visual and auditory space, and body surface (Stein, 1984). Importantly, these representations are integrated such that stimuli which are perceived by multiple sensory systems will initiate SC-

\footnotetext{
Received 0ct. 3, 2017; revised March 13, 2018; accepted March 16, 2018

Author contributions:B.E.B. and S.G.L. designed research; B.E.B., J.K.S., and S.G.L. performed research; B.E.B. and J.K.S. analyzed data; B.E.B., J.K.S., and S.G.L. wrote the paper.

This work was supported by the Natural Sciences and Engineering Research Council of Canada, the Canadian Institutes of Health Research, and the Canada Foundation for Innovation.

The authors declare no competing financial interests.

Correspondence should be addressed to Dr. Blake E. Butler, Department of Psychology, University of Western Ontario, 1151 Richmond Street North, London, Ontario N6A 5C2, Canada. E-mail: bbutler9@uwo.ca.

DOI:10.1523/JNEUROSCI.2858-17.2018

Copyright $\odot 2018$ the authors $\quad 0270-6474 / 18 / 384048-11 \$ 15.00 / 0$
}

mediated orienting responses with a greater likelihood than if one modality is stimulated in isolation (e.g., Stein et al., 1989). This multisensory integration is dependent upon inputs from sensory cortex, arising primarily from the anterior ectosylvian sulcus (AES), a region where representations of vision (the anterior ectosylvian visual area [AEV]) (Olson and Graybiel, 1987; Benedek et al., 1988; Jiang et al., 1994), audition (the auditory field of the anterior ectosylvian sulcus [fAES]) (Clarey and Irvine, 1986; Meredith and Clemo, 1989), and somatosensation (the fourth somatosensory cortex [S4]) (Clemo and Stein, 1982, 1983) exist in close proximity. If cortical input from these regions is disrupted, SC neurons remain responsive to sensory stimuli, as they are in receipt of inputs from a broad array of sensory brain regions in addition to those located along the AES; however, the output of SC neurons reflects the strongest unisensory input rather than a synergistic combination of multisensory inputs (Jiang et al., 2001; Alvarado et al., 2009). 
Table 1. Cases examined

\begin{tabular}{llll}
\hline Case no. & Age at deafening & Age of perfusion & Duration of deafness \\
\hline W245 & $15 \mathrm{~d}$ & $6 \mathrm{mo}, 17 \mathrm{~d}$ & $6 \mathrm{mo}, 2 \mathrm{~d}$ \\
W246 & $16 \mathrm{~d}$ & $7 \mathrm{mo}, 17 \mathrm{~d}$ & $7 \mathrm{mo}, 1 \mathrm{~d}$ \\
W264 & $18 \mathrm{~d}$ & $5 \mathrm{yr}, 2 \mathrm{mo}$ & $5 \mathrm{yr}, 1.4 \mathrm{mo}$ \\
W270 & $10 \mathrm{~d}$ & $2 \mathrm{yr}, 10 \mathrm{mo}$ & $2 \mathrm{yr}, 9.6 \mathrm{mo}$ \\
W272 & $11 \mathrm{~d}$ & $2 \mathrm{yr}, 11 \mathrm{mo}$ & $2 \mathrm{yr}, 10.6 \mathrm{mo}$ \\
\hline
\end{tabular}
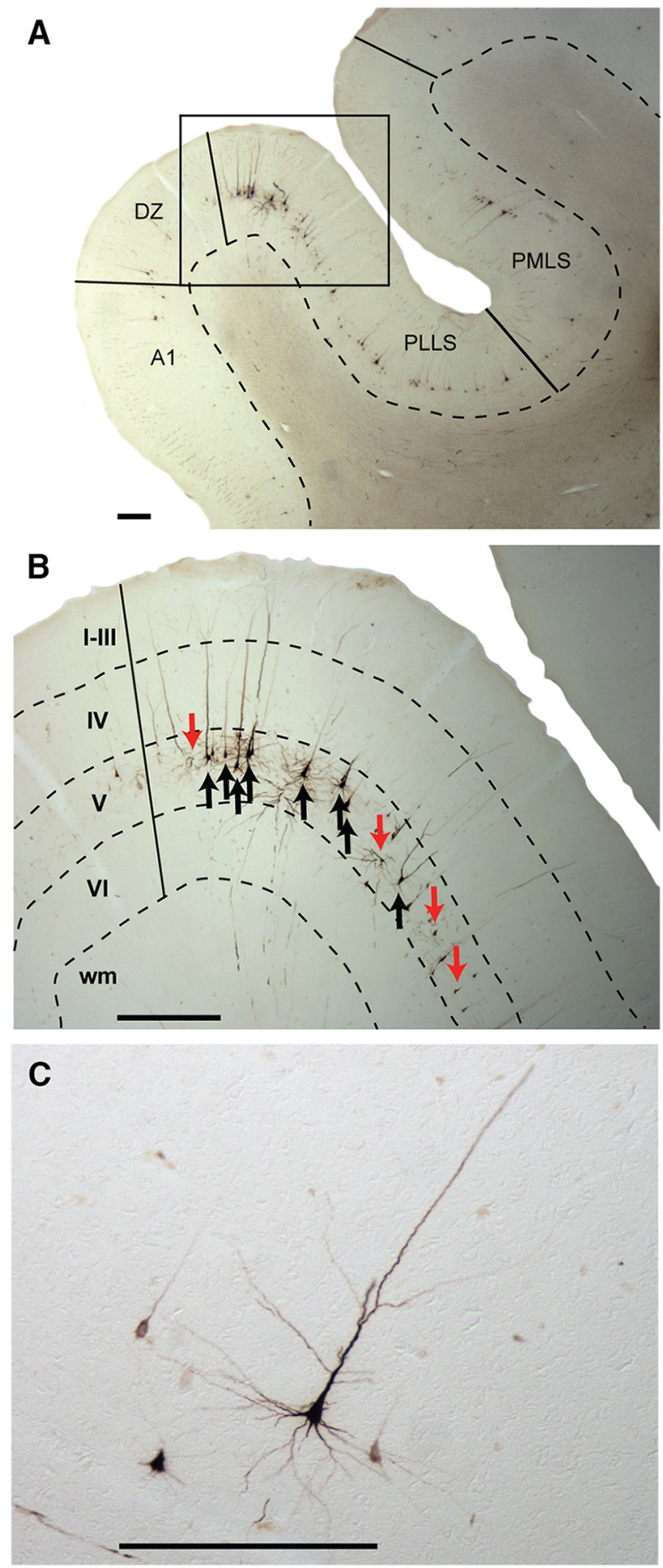

Figure 1. Labeled neurons in the PLLS. Dashed lines indicate the boundaries between gray and white matter $(\boldsymbol{A})$ or between cortical layers $(\boldsymbol{B})$. Black arrows indicate labeled neurons. To be considered a labeled neuron, the nucleus and the entirety of the somatic membrane had to be present. Red arrows point to neurons that are too faintly labeled and were not included in the count. C, Detailed view of a labeled neuron. Scale bar, $500 \mu \mathrm{m}$. DZ, Dorsal zone of auditory cortex.

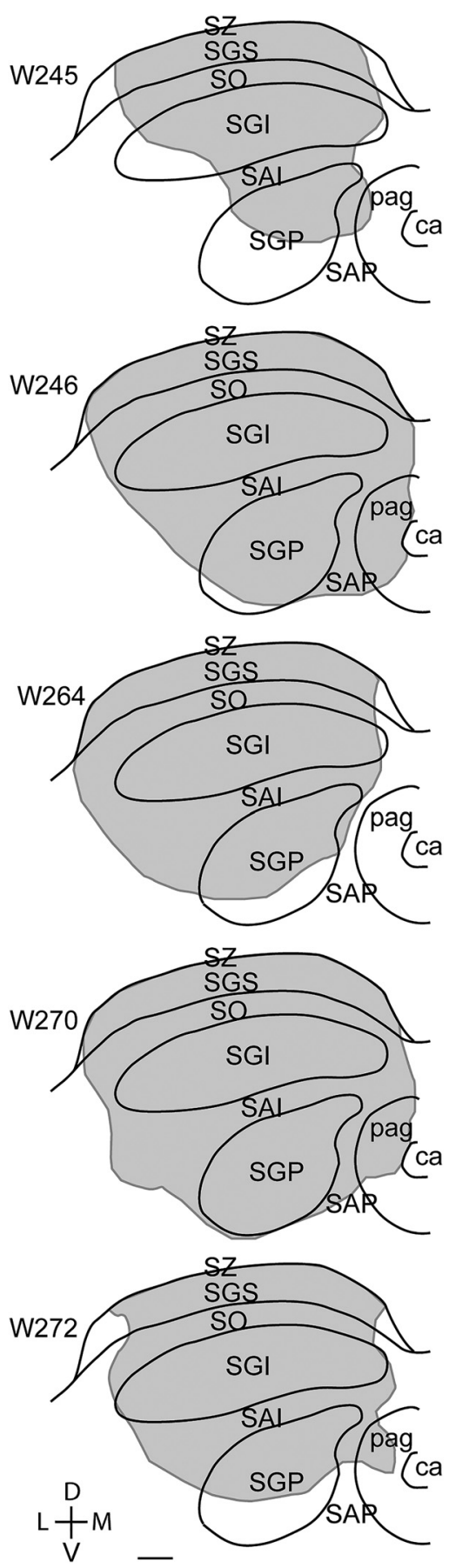

Figure 2. Schematic representations of tracer spread across the coronal plane of the SC for each animal in the present study, presented on a standardized SC. The tracer spread throughout the superficial and deep layers of the SC. In some cases, tracer spread medially into the periaqueductal gray (pag), but there was no evidence of spread into the contralateral SC or ipsilateral pretectum in any case. Scale bar, $500 \mu \mathrm{m}$. ca, Anterior commissure; SAl, stratum album intermediale; SAP, stratum album profundum; SGI, stratum griseum intermediale; SGP, stratum griseum profundum; SGS, stratum griseum superficiale; $\mathrm{SO}$, stratum opticum; $\mathrm{SZ}$, stratum zonale.

Electrophysiological examinations of the response properties of SC neurons have demonstrated that the development of multisensory integration is a slow process that depends upon postnatal experience with multisensory stimuli (Wallace and Stein, 2001; Stein, 2012; Xu et al., 2012). Although this allows for a system optimally tuned to those stimuli encountered most fre- 
quently in an individual's environment, it also leaves the system vulnerable to periods of impoverished input. A number of studies have sought to address the functional consequences of periods of abnormal experience in which the pairing of stimuli across sensory modalities does not occur. For example, sensory integration within the SC is disrupted in cats reared in darkness, as the requisite auditory-visual experience is precluded (Wallace et al., 2004; Yu et al., 2010). Such periods of dark rearing dramatically alter modulatory corticotectal inputs arising from regions along the banks of AES such that their influence is reduced in specificity, and insufficient to support multisensory integration (Yu et al., 2013). Similarly, SC neurons of animals raised in the presence of a broadband noise signal that masks environmental sounds (and thus precludes multisensory perception) show altered receptive field properties and dramatically reduced multisensory integration ( $\mathrm{Xu}$ et al., 2011). These studies suggest that early periods of abnormal sensory development dramatically disrupt the functional connectivity between the cortex and SC.

A number of recent studies have addressed the hypothesis that changes in anatomical connectivity give rise to functional plasticity following hearing loss in the cat. However, quantifications of thalamocortical and corticocortical projections have revealed a striking similarity between patterns of connectivity in normal hearing and deaf animals. For example, no significant evidence of crossmodal plasticity has been observed in cortical projections to the primary auditory cortex (Chabot et al., 2015), the posterior auditory field (Butler et al., 2016a), the auditory field of the anterior ectosylvian sulcus (Meredith et al., 2016), or the second auditory cortex (Butler et al., 2018). In other brain regions including the dorsal zone of auditory cortex (Kok et al., 2014) and the anterior auditory field (Wong et al., 2015), only small changes in the proportion of projections from visual and/or somatosensory regions have been observed. However, to our knowledge, no study has provided a comprehensive overview of how the underlying corticotectal connectivity is altered by sensory loss. Thus, the present study examines corticotectal projections from across the cat cortex following early-onset deafness, with a particular focus on those regions known to contribute to multisensory integration and orienting behavior mediated by the SC.

\section{Materials and Methods}

Overview. Corticotectal projections were examined in 5 adult $(>6$ months, 2 male, 3 female) short-haired domestic cats that were otoxically deafened perinatally. Cats were born in-house from pregnant queens obtained from a USDA-licensed commercial animal breeding facility (Liberty Laboratories) and were housed in enriched colony environ-
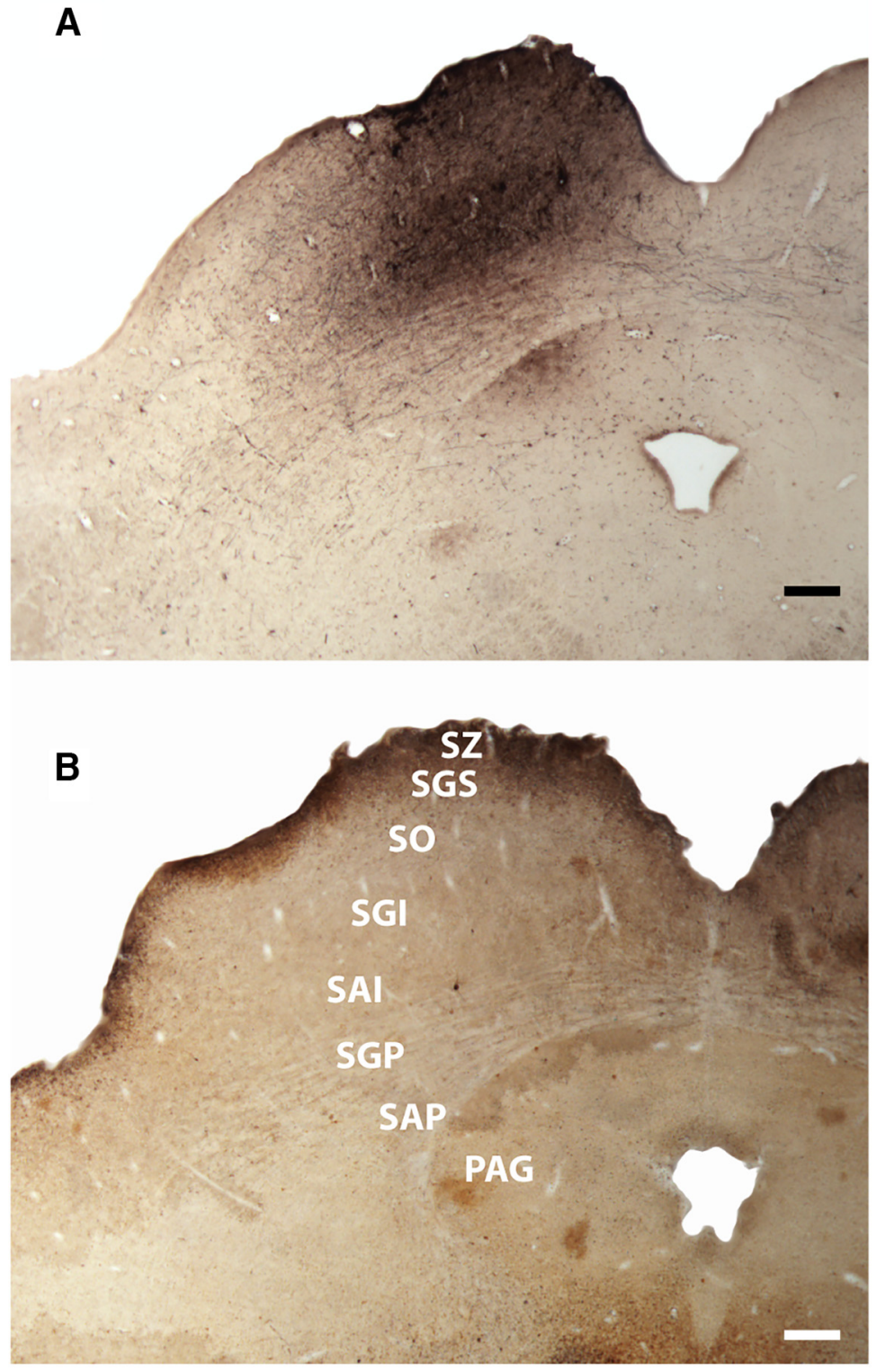

Figure 3. Photomicrographs of coronal sections through the SC of Case W245. A, Injection site. $\boldsymbol{B}$, Cytochrome oxidase series with layers of the $S C$ indicated. The BDA tracer spread into all the layers of the $S C$, with minimal spread into the periaqueductal gray. Scale bar, $500 \mu \mathrm{m}$. SZ, stratum zonale; SGS, stratum griseum superficiale; SO, stratum opticum; SGI, stratum griseum intermediale; SAI, stratum album intermediale; SGP, stratum griseum profundum; SAP, stratum album profundum.

ments with free access to food and water. At least 6 months following deafening, the retrograde tracer biotinylated dextran amine (BDA; 3000 MW [10\%], Vector Laboratories) was deposited into the left SC. After a 2 week tracer transport period, cats were perfused and brain tissue was processed for neuronal labeling (Table 1). All surgical and experimental procedures were conducted in accordance with the National Research Council's Guidelines for the care and use of mammals in neuroscience and behavioral research and the Canadian Council on Animal Care's Guide to the care and use of experimental animals and were approved by the University of Western Ontario Animal Use Subcommittee of the University Council on Animal Care.

Ototoxic deafening. Cats were ototoxically deafened around the time of hearing onset ( $<3$ weeks postnatal) (Shipley et al., 1980). Auditory brainstem responses were measured before and during the deafening procedure to assess hearing thresholds. Subdermal EEG leads were placed above the ears in a vertex to mastoid configuration. Auditory stimuli (0-80 dB nHL, $0.1 \mathrm{~ms}$ squarewave clicks) were presented through ER3A foam insert headphones (Etymotic Research). Animals 
Table 2. Cortical field-level changes between normal hearing and early-deaf animals ${ }^{a}$

\begin{tabular}{|c|c|c|c|c|c|c|c|c|c|c|c|c|c|c|c|c|c|}
\hline & \multicolumn{9}{|c|}{ Visual } & \multicolumn{6}{|c|}{ Auditory } & \multicolumn{2}{|c|}{$\begin{array}{c}\text { Motor and } \\
\text { Somatosensory }\end{array}$} \\
\hline & 7 & 17 & 18 & 19 & $20 \mathrm{a}$ & ALLS & AMLS & PLLS & PMLS & $\mathrm{A} 1$ & $\mathrm{dPE}$ & fAES & IN & iPE & $\mathrm{vPE}$ & 5 & S4 \\
\hline Normal hearing & 1.51 & 36.42 & 5.68 & 7.61 & 1.34 & 2.61 & 1.93 & 12.56 & 7.54 & 0.28 & 0.06 & 4.60 & 0.25 & 0.33 & 0.98 & 0.52 & 0.42 \\
\hline Early-deaf & 2.87 & 18.90 & 3.72 & 9.59 & 1.90 & 2.69 & 0.98 & 6.14 & 3.96 & 1.11 & 2.56 & 0.34 & 2.85 & 1.26 & 1.18 & 3.09 & 1.75 \\
\hline$p$ & 0.07 & 1.0 & 1.0 & 1.0 & 1.0 & 1.0 & 0.83 & 0.29 & 0.86 & ${ }^{*} 0.039$ & 0.19 & ${ }^{*} 0.047$ & 0.071 & 0.19 & 0.90 & 0.63 & 1.0 \\
\hline
\end{tabular}

${ }^{a}$ Fields comprising $>1 \%$ of labelled cells in at least one population are presented and are grouped by modality: visual, auditory, motor, and somatosensory regions. ALLS, Anterolateral lateral suprasylvian area; AMLS, anteromedial lateral suprasylvian area; $\mathrm{A1}$, primary auditory cortex; $\mathrm{dPE}$, dorsal posterior ectosylvian gyrus; IN, insular auditory cortex; $\mathrm{PEE}$, intermediate posterior ectosylvian gyrus; $\mathrm{VPE}$, ventral posterior ectosylvian gyrus.

*Significant differences (corrected $p$ values, Mann-Whitney tests).

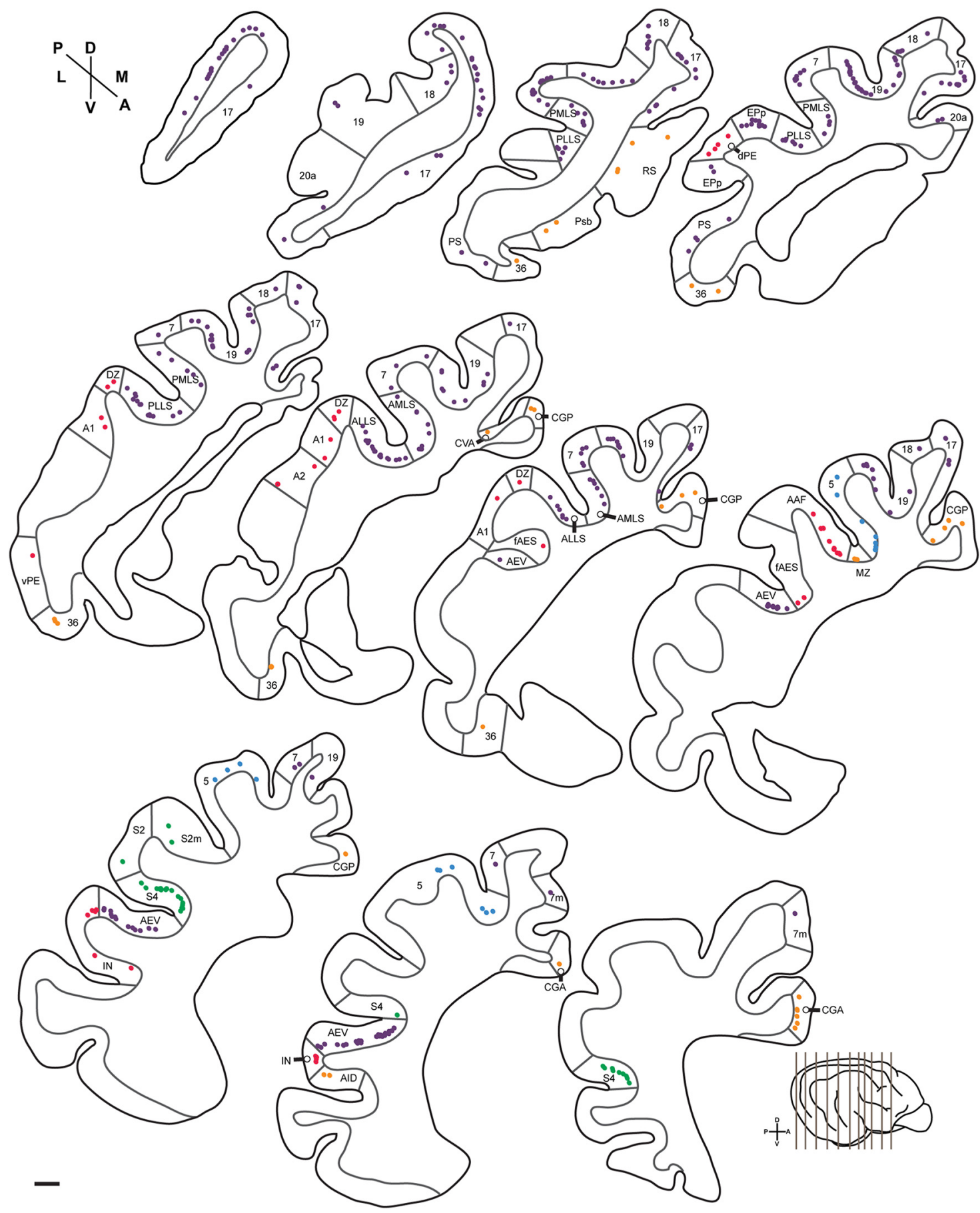

Figure 4. Representative distribution of visual (purple), auditory (red), somatosensory (green), motor (blue), and limbic (yellow) corticotectal projections. The lateral schematic of the brain (bottom right) shows the levels from which these coronal sections through the cortex were taken. Bottom left, Scale bar, $1 \mathrm{~mm}$. A1, primary auditory cortex; A2, second auditory cortex; AAF, anterior auditory field; CGA, anterior cingulate; CGP, posterior cingulate; CVA, cingulate visual area; DZ, dorsal zone of auditory cortex; EPp, posterior division of the posterior ectosylvian gyrus; IN, auditory insular cortex; PS, posterior suprasylvian visual area; RS, retrosplenial area. 
were anesthetized by inhalation of oxygen $(1 \mathrm{~L} / \mathrm{min})$ and isoflurane $(5 \%$ to effect for induction, $1.5 \%-2 \%$ to maintain), and an intravenous catheter was inserted into the cephalic vein of the forelimb. Deafening was induced by the coadministration of sodium Edecrin (to effect 35-60 $\mathrm{mg} / \mathrm{kg}$, i.v.) and kanamycin $(300 \mathrm{mg} / \mathrm{kg}$, s.c.). This method is known to selectively destroy hair cells in the cochlea and result in permanent, profound hearing loss (Xu et al., 1993). Once auditory brainstem responses were absent at $80 \mathrm{~dB}$, infusion of sodium Edecrin was terminated and replaced by lactated Ringer's solution $(4 \mathrm{ml} / \mathrm{kg}$, i.v.). The catheter was removed, and the animal was allowed to recover from anesthesia. A second auditory brainstem response was recorded 3 months later to confirm that thresholds were elevated $>80 \mathrm{~dB}$.

Surgical procedures. Each cat was fasted and lightly anesthetized with ketamine $(4 \mathrm{mg} / \mathrm{kg}$, i.m. ) and Dexdomitor $(0.020 \mathrm{mg} / \mathrm{kg}$, i.m.) the afternoon before surgery to insert an indwelling feline catheter into the cephalic vein for the administration of intravenous medications. The anti-inflammatory dexamethasone $(0.5 \mathrm{mg} / \mathrm{kg}$, i.v. $)$ was then administered. On the day of surgery, atropine $(0.02 \mathrm{mg} / \mathrm{kg}$, s.c. $)$ was administered to minimize alimentary and respiratory secretions, followed by dexamethasone $(0.5 \mathrm{mg} / \mathrm{kg}$, i.v. $)$, and buprenorphine $(0.01 \mathrm{mg} / \mathrm{kg}$, s.c. $)$. General anesthesia was induced and maintained with sodium pentobarbital ( $25 \mathrm{mg} / \mathrm{kg}$ i.v., to effect). To suppress the gag reflex and allow for intubation, Cetacaine (Cetylite Laboratories) was sprayed onto the pharyngeal walls. Neosporin (Kirkland), an ophthalmic ointment, was applied to protect the cornea. The cat was stabilized in a stereotaxic frame (David Kopf Instruments), and its head was shaved and prepared for surgery using aseptic procedures. Body temperature, heart rate, respiration rate, and blood pressure were continuously monitored. A water-filled heating pad (Gaymar) was used to maintain a core temperature of $37^{\circ} \mathrm{C}$.

A midline incision was made, and the left temporalis muscle was reflected laterally. A craniotomy $\left(\sim 2 \mathrm{~cm}^{2}\right)$ was made over the marginal, posterolateral, and middle suprasylvian gyri of the left hemisphere. The skull piece was stored in sterile saline for later replacement and the dura was reflected laterally. Mannitol (25 mg/kg, i.v.) was infused to permit lateral displacement of the hemisphere, and to aid in visualization of the SC (Lomber et al., 2001). In addition, the posterior half of the splenium of the corpus callosum was ablated by aspiration to allow for visualization of the dorsal surface of the SC and to permit entrance of the injection pipette.

Tracer deposits. BDA (3000 MW, [10\%] Vector Laboratories) was injected through a glass syringe (Hamilton) into the left SC. The tracer was deposited in three locations across the SC (anterior medial, posterior medial, and lateral injection sites) at two depths (1000 and $2000 \mu \mathrm{m})$ to ensure both the deep and superficial SC layers were exposed. A volume of $0.3 \mu \mathrm{l}$ was deposited at each depth in each of the three locations, for a total injection volume of $1.8 \mu \mathrm{l}$. Following each deposit, the pipette remained stationary for $5 \mathrm{~min}$. Any leakage of BDA was removed by flushing with sterile saline to prevent tracer contamination of surrounding tissue. When all 6 injections were completed, the bone piece was replaced and secured with dental acrylic and stainless-steel skull screws followed by suturing of the incision with 3-0 silk.

Postsurgical procedures. Following extubation and removal of the indwelling catheter, half-strength lactated Ringer's solution $(20 \mathrm{ml} / \mathrm{kg}$, s.c.) was administered, as necessary, for $4 \mathrm{~h}$. Respiration rate, blood pressure, and heart rate were monitored until the animal was sternally recumbent. Buprenorphine $(0.01 \mathrm{mg} / \mathrm{kg}$, s.c.) was administered every $6 \mathrm{~h}$ for the first $24 \mathrm{~h}$, and every 12 hours for the next $48 \mathrm{~h}$. For $6 \mathrm{~d}$ following surgery, dexamethasone $(0.05 \mathrm{mg} / \mathrm{kg}$ on day 1 and 2 , decreasing by $0.01 \mathrm{mg} / \mathrm{kg}$ each day thereafter, s.c.) was given every $24 \mathrm{~h}$. In all cases, recovery was uneventful.

Perfusion and tissue processing. Two weeks following BDA injections, the cephalic vein was cannulated and the cat was deeply anesthetized (sodium pentobarbital, $35 \mathrm{mg} / \mathrm{kg}$, i.v.). An anticoagulant (heparin, $10,000 \mathrm{U} ; 1 \mathrm{ml})$ and a vasodilator ( $1 \%$ sodium nitrite, $1 \mathrm{ml}$ ) were administered intravenously, and the animal was perfused intracardially through the ascending aorta. Physiological saline was perfused for 10 min, followed by aldehyde fixatives (4\% PFA) for $20 \mathrm{~min}$ and $10 \% \mathrm{su}-$ crose for $20 \mathrm{~min}$. All solutions were buffered to a $\mathrm{pH}$ of 7.4 with $0.1 \mathrm{M}$

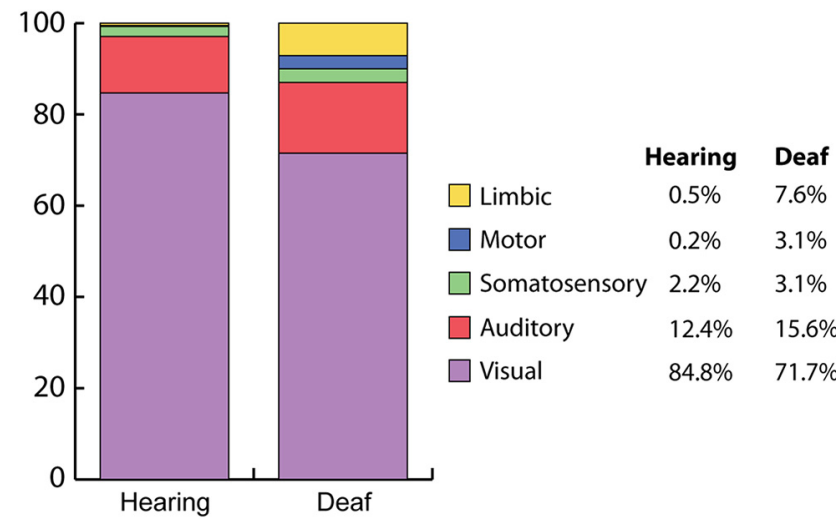

Figure 5. Distribution of corticotectal projections by modality in the cortex for the animals described in the current study (Deaf). Data from hearing animals, previously reported by Butler et al. (2016b), are included for comparison.

Sorenson's buffer and infused at a rate of $100 \mathrm{ml} / \mathrm{min}$. The brain was stereotaxically blocked (coronal plane at Horsley-Clarke level A25), removed, and placed in $30 \%$ sucrose in $0.1 \mathrm{M}$ Sorenson's buffer to cryoprotect it for histological processing.

Once the brain sank, it was frozen and cut in $60 \mu \mathrm{m}$ coronal sections using a cryostat (CM 3050s; Leica Microsystems). Six series of sections at $360 \mu \mathrm{m}$ intervals were collected, and four series were processed for one of the following: (1) BDA using the avidin-biotin peroxidase method (Veenman et al., 1992) (Covance Research Products); (2) monoclonal antibody SMI-32 (Covance Research Products: RRID:AB_2315331); (3) Nissl stain; and (4) cytochrome oxidase (Payne and Lomber, 1996). The avidin-biotin peroxidase method was used to reveal the presence of labeled neurons, whereas the SMI-32 series was used for examining cytoarchitecture and defining cortical areal borders. Finally, the Nissl and cytochrome oxidase series assisted with collicular subdivision and laminar distinctions. The remaining two series were retained as spares. Following staining, the tissue was mounted onto gelatin-coated slides, air dried, and coverslipped.

Data analysis. A Nikon E600 microscope mounted with a DXM 1200 digital camera was used to visualize BDA-labeled neurons. Neurolucida software (MicroBrightfield) was used to plot and quantify labeled cells, and to trace the contours of sections and injection sites. To prevent the inclusion of artifactual labeling, neurons were only considered labeled if the entire somatic membrane was present and the nucleus was visible (Fig. 1). Partial cell bodies or dendritic branches alone were not counted. The focal level was adjusted throughout the $z$ plane of each section to ensure that the full thickness was examined.

For each animal, areal borders were delineated based on cytoarchitectural differences, sulcal and gyral patterns, and previously described SMI-32 and Nissl staining profiles. In the visual cortex, borders between the posterior lateral suprasylvian (PLLS) and posteromedial lateral suprasylvian (PMLS) areas were placed on the lateral bank of the middle suprasylvian sulcus, and borders between the dorsal and ventral lateral suprasylvian areas were placed on the dorsal bank of the posterior limb of the suprasylvian sulcus, which is supported by cytoarchitectonic methods in the visual system (van der Gucht et al., 2001). In the auditory cortex, areal borders were assigned based on previously published criteria surrounding changes in the patterns of SM1-32 labeling (Mellott et al., 2010; Wong et al., 2014). Motor cortical fields were delineated based primarily on Nissl staining profiles (Clascá et al., 1997). Any labeled neurons lying along the transitional zone between cortical fields were assigned equally to the two areas.

The raw number of labeled neurons in each cortical field was converted to a proportion of the total number of labeled cells on an individual animal basis to account for differences in tracer uptake and histological processing. The median proportion of cells was then calculated as a measure of group central tendency for each cortical field. Finally, the number of cells in each modality (visual, auditory, somatosensory, motor, limbic) was determined. 


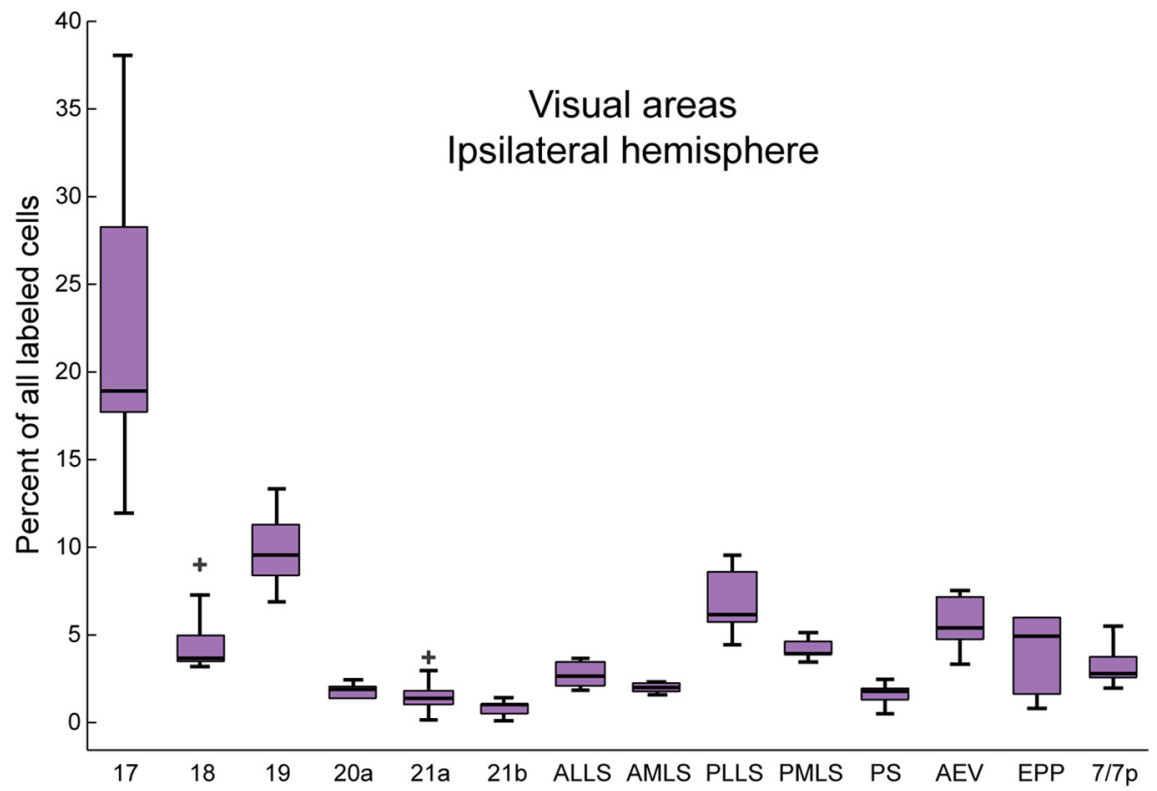

Figure 6. Box-and-whisker plot illustrating the distribution of visual corticotectal projections by cortical area. $y$ axis indicates the percentage of labeled neurons and whiskers extend a maximum of 1.5 times the interquartile range.,+ Outlier. The largest connections from the visual cortex originate from the primary area 17 (median $=18.9 \%$ ), area 19 (median $=9.6 \%$ ), and PLLS (median $=6.1 \%)$. Other visual areas involved in visual orienting behavior (18, PMLS) show weaker connections with the SC (median of $3.7 \%$ and $4.0 \%$, respectively). ALLS, anterolateral lateral suprasylvian area; AMLS, anteromedial lateral suprasylvian area; PS, posterior suprasylvian visual area; EPP, posterior division of the posterior ectosylvian gyrus.

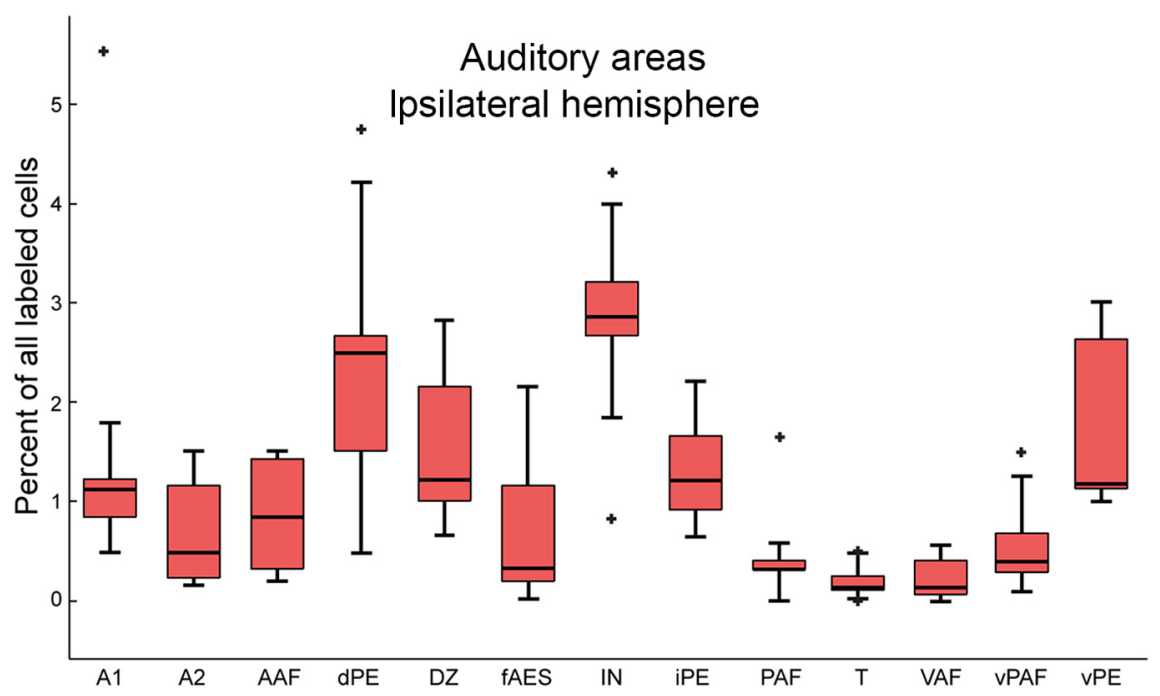

Figure 7. Box-and-whisker plot illustrating the distribution of auditory corticotectal projections by cortical area. $y$ axis indicates the percentage of labeled neurons and whiskers extend a maximum of 1.5 times the interquartile range.,+ Outlier. Auditory projections to the $\mathrm{SC}$ are diffuse, with each of the 13 regions comprising a small proportion of labeled cells (all $<3 \%$ ). A1, primary auditory cortex; $A 2$, second auditory cortex; AAF, anterior auditory field; $\mathrm{dPE}$, dorsal posterior ectosylvian gyrus; DZ, dorsal zone of auditory cortex; IN, auditory insular cortex; iPE, intermediate posterior ectosylvian gyrus; PAF, posterior auditory field; T, temporal auditory cortex; VAF, ventral auditory field; VPAF, ventral posterior auditory field; vPE, ventral posterior ectosylvian gyrus.

Experimental design and statistical analysis. Differences in modalitylevel projections to the deaf SC were computed using a Kruskal-Wallis test, with post hoc pairwise comparisons computed according to the Conover Method with a Holm familywise error rate correction applied. At the individual field level, Bonferroni-corrected Mann-Whitney tests were used to compare the data from the current study to previously reported data from hearing animals (Butler et al., 2016b) for any field in which the proportion of labeled cells exceeded a threshold of $1 \%$. Because the signed-rank procedure that comprises the Mann-Whitney test is not robust to multiple ties, this thresholding procedure effectively eliminated comparisons between cortical regions, which typically comprised $0 \%$ of labeled cells in more than 1 animal.

\section{Results}

\section{Tracer spread}

Five cats received deposits of BDA that spread throughout the superficial and deep layers of the left SC. The injection sizes are directly comparable with those used previously to quantify projections in hearing animals (Meredith and Clemo, 1989; Chabot et al., 2013; Butler et al., 2016b). Tracer spread following injection is illustrated for each animal on a normalized coronal section for comparison (Fig. 2). In all cases, the tracer was exposed to axon terminals in stratum griseum superficiale, stratum griseum intermediale, and stratum griseum profundum and covered the majority of the SC (Fig. 3). There was no evidence of spread into any portion of the pretectal nuclei or the inferior colliculus in any case. In some cases, there was exposure of tracer to the lateral portions of the periaqueductal gray. There was no evidence of tracer spread to the contralateral SC. Based on these results, no cases were excluded from the data analysis.

\section{Neuronal labeling patterns}

We have previously published a similar analysis of connectivity in normal hearing animals (Butler et al., 2016b) that will serve as a basis for comparison. Table 2 illustrates changes in the proportion of labeled cells between the two studies. It is worth noting that tracer injections made in both of these studies sought to quantify projections to the entirety of the SC. This includes both the superficial layers (stratum zonale, stratum griseum superficiale, stratum opticum), whose cortical inputs arise almost entirely from visual cortical areas (Kawamura et al., 1974; Baleydier et al., 1983), and the deeper layers (stratum griseum intermediale, stratum album intermediale, stratum griseum profundum, stratum album profundum), whose inputs arise from regions across cortex, and which have been shown to be the site of multisensory integration in SC (Baleydier et al., 1983; Wallace et al., 1993). While this approach provides a comprehensive quantification of corticotectal inputs, it also means that a greater proportion of inputs were found to arise from visual cortical regions than if deep layers had been targeted specifically. Thus, while the SC as a whole receives $71 \%$ of its cortical projections from visual regions, the same is not true of multisensory neurons of the SC. All cortical neurons showing positive labeling were counted as described 
above. In the cerebrum, the overwhelming number of labeled neurons were identified in the hemisphere ipsilateral to the injection site (median $=96.3 \%$ ), with only a small number of labeled cells identified in the contralateral hemisphere ( median $=3.7 \%)$. Moreover, labeling was most dense in the dorsal and lateral aspects of the cerebrum, with few labeled cells in more ventral areas. Within the ipsilateral cortex, neurons were located throughout the marginal, posterolateral, and suprasylvian gyri. The suprasylvian and anterior ectosylvian sulci also contained large numbers of labeled cells (a representative plot of labeled cells in one animal [W264] is presented in Fig. 4). Likewise, the majority of labeled cells in the contralateral hemisphere were confined to the suprasylvian and ectosylvian sulci.

On an individual animal basis, the labeled neurons in each cortical area are expressed as a percentage of the total number of labeled cells in the entire cortex to allow for meaningful comparisons between animals, and to previous work in hearing animals (the raw number of cells labeled was not different between groups [hearing: median $=6211$, deaf: median $=$ $5633, \mathrm{~W}=9 p=0.55])$. A Kruskal-Wallis test revealed significant differences between projections to the SC at a modality level $\left(\chi_{(4)}^{2}=20.35, p=0.0004\right)$. As expected, the visual cortex $(71.7 \%)$ contained significantly more labeled cells that any other modality following retrograde injection into the SC (all $p<0.01$ ), with the input from auditory cortex (15.6\%), exceeding that of the somatosensory (3.1\%; $p<0.01)$, motor $(3.1 \% ; p<0.01)$, and limbic cortices $(7.6 \%$; $p=0.03$; Fig. 5).

\section{Labeling profile of individual cortical fields}

Labeling of cells in the visual cortex was evident across the entire visual field, from the most posterior to the most anterior portions of visual cortex, representing the fovea and the visual periphery, respectively (Tusa et al., 1981). The primary visual cortex (area 17) showed the highest proportion of neurons projecting to the SC $($ median $=18.9 \%)$, followed by the remaining visual areas that are known to be involved in visual orienting behaviors, including areas 18 and 19, and the PLLS and PMLS areas (Fig. 6). Substantial proportions of projections were also observed to arise from the AEV (5.4\%) and the posterior aspect of the posterior ectosylvian gyrus $(5.0 \%)$. Each of the remaining visual cortical fields contained $<3 \%$ of the total labeled cells.

Auditory cortical regions comprised $15.6 \%$ of the total number of labeled cells, with a small number of neurons observed in each of the 13 auditory cortical regions. The largest proportions of auditory projections were observed to arise from the insular auditory cortex $(2.9 \%)$ and the dorsal aspect of the posterior
Ipsilateral somatosensory areas

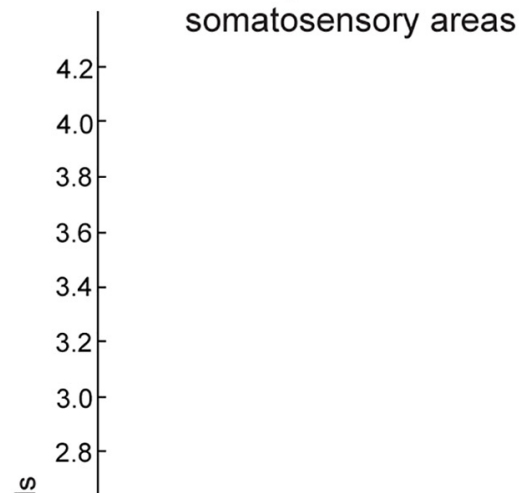

Figure 8. Box-and-whisker plot illustrating the distribution of somatosensory and motor corticotectal projections by cortical Outlier. The primary somatosensory area does not have a direct projection to the SC. S2, second somatosensory cortex; S2m, medial division of the second somatosensory cortex; S4, fourth somatosensory cortex; S5, fifth somatosensory cortex. ectosylvian gyrus $(2.6 \%)$, with the remaining projections ranging between $0.3 \%$ and $1.3 \%$ of the total number of labeled cells (Fig. 7). Critically, the current study reveals that the median proportion of labeled cells in fAES is decreased by an order of magnitude in early-deaf relative to normal hearing animals ( $0.3 \%$ vs $4.7 \%$; $\mathrm{W}=25$, corrected $p=0.047)$. Conversely, the proportions of labeled cells in 11 of the 12 remaining fields of auditory cortex are increased in the deaf; however, only in primary auditory cortex did the increase reach statistical significance $(\mathrm{W}=0$, corrected $p=0.039$ ).

In somatosensory and motor cortices, labeled neurons were observed in a small number of fields. The second $(0.3 \%)$, medial second $(0.3 \%)$, fourth $(1.8 \%)$, and fifth $(0.1 \%)$ somatosensory areas (Fig. 8) were each shown to contain a small proportion of labeled cells. Although primary somatosensory cortex has been shown to play a role in orienting behavior, we found no evidence of a direct projection to the SC. Within the motor cortex, area 5 has been shown to be involved with generating orienting responses and made the most substantial proportional projection to the SC (3.1\%); an additional, smaller input was also observed to originate from area $4(0.3 \%)$. 


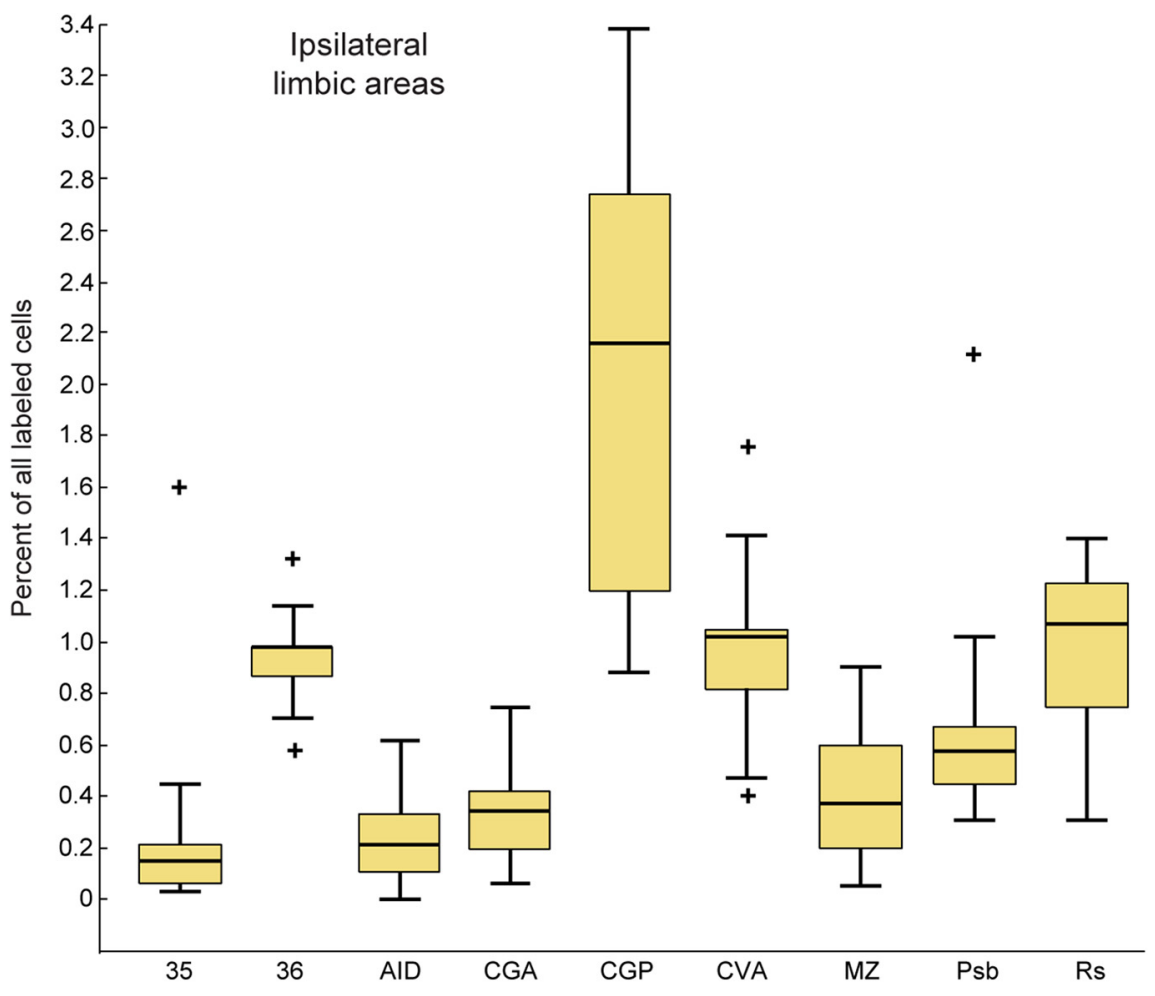

Figure 9. Box-and-whisker plot illustrating the distribution of limbic corticotectal projections by cortical area. $y$ axis indicates the percentage of labeled neurons and whiskers extend a maximum of 1.5 times the interquartile range.,+ 0 utlier. The largest limbic projection to the SC arises from the posterior cingulate (2.2\%). AID, dorsal division of the agranular insular area; CGA, anterior cingulate; CGP, posterior cingulate; CVA, cingulate visual area; MZ, multisensory zone; Psb pre- and parasubiculum; Rs, retrosplenial area.

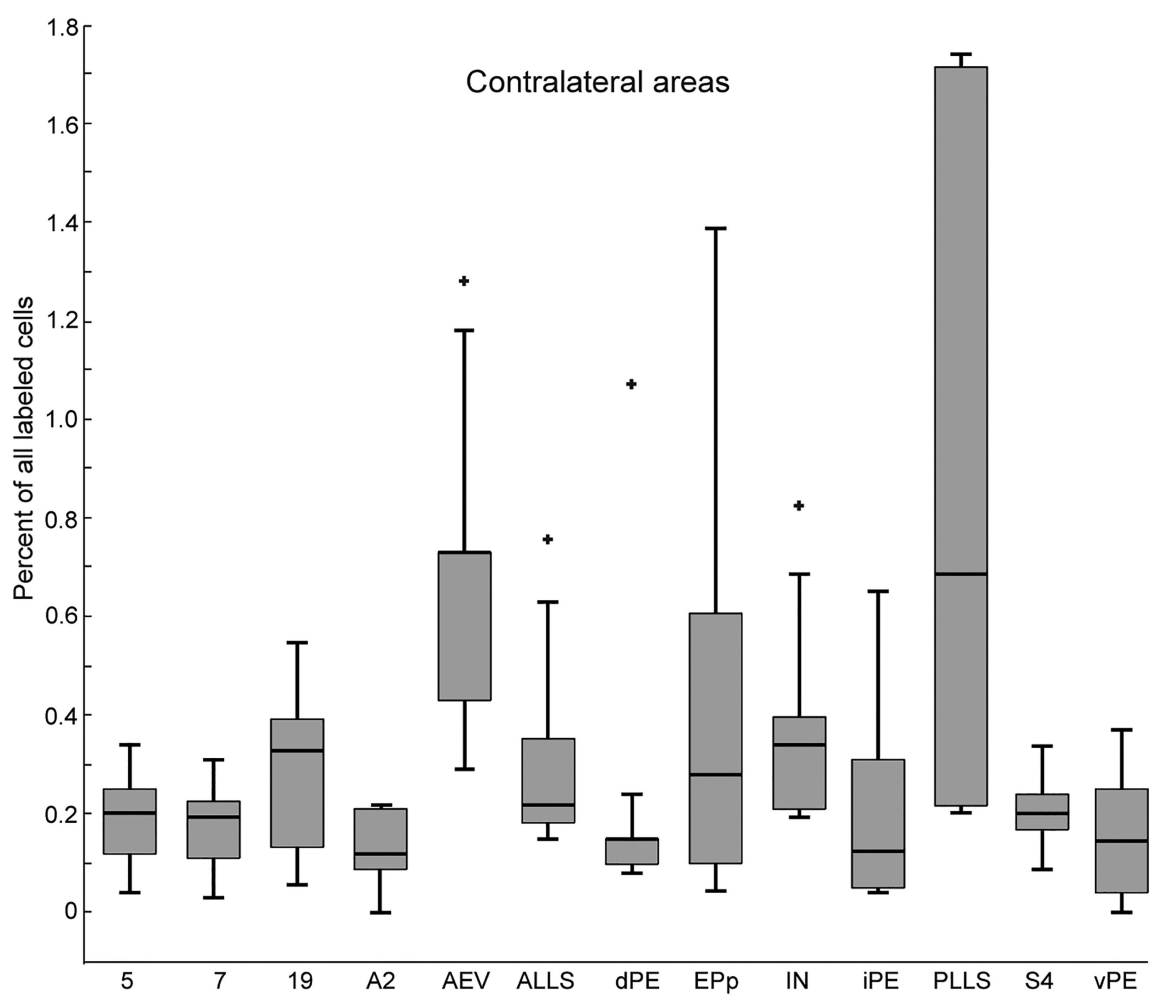

Figure 10. Box-and-whisker plot illustrating the distribution of contralateral corticotectal projections by cortical area. $y$ axis indicates the percentage of labeled neurons and whiskers extend a maximum of 1.5 times the interquartile range.,+ 0 utlier. Each of the contralateral cortical areas has a projection accounting for $<1 \%$ of total labeled neurons.
In limbic cortex, labeled cells were identified within a number of areas (Fig. 9). The largest proportion of labeled cells was located in the posterior cingulate area $(2.2 \%)$, followed by the retrosplenial area $(1.1 \%)$, and the cingulate visual area $(1.0 \%)$. All other areas contained $<1 \%$ of labeled cells.

A much smaller proportion of cells were observed in the contralateral cortex compared with the ipsilateral hemisphere $(7.9 \%$ vs 92.1\%). Within the contralateral hemisphere, no cortical region accounted for $>1 \%$ of the total number of labeled cells. The largest proportions of projections were observed to originate in the contralateral visual areas AEV and PLLS (each 0.7\%; Fig. 10).

\section{Discussion}

This comprehensive quantification of cortical projections to the SC in early-deaf cats comprises the first examination of reorganized sensory cortical outputs following hearing loss. As in hearing animals, nearly all corticotectal projections in deaf animals arise from layer $\mathrm{V}$ of regions ipsilateral to SC injection (median $=99 \%$ ). However, stark contrasts exist between groups in both modality-level and individual field-level patterns of labeling.

\section{Modality-level changes}

Figure 5 compares modality-level patterns of corticotectal projections in hearing (Butler et al., 2016b) and deaf animals (present study). Interestingly, deafness resulted in a decreased proportion of labeled cells in visual cortex and increases in all other modalities. Most strikingly, proportions from limbic areas increased from $0.5 \%$ in hearing animals to $7.6 \%$ in the deaf, which likely relates to the function of these cortical efferents. Alvarado et al. (2009) suggest that corticotectal modulation of SC function confers integrative flexibility, such that multisensory enhancement is sensitive to behavioral context. This could be achieved within a Bayesian framework whereby independently weighted stimulus representations are fused to generate optimal percepts. This would involve weighting different sensory representations to reflect their relative reliability (e.g., Morgan et al., 2008). However, if learned stimulus associations are to be incorporated, top-down cortical influence would be crucial. In deafness, SC neurons receive no representation of the auditory world and may rely upon stronger projections from limbic cortices to provide behaviorally relevant information to complement inputs from the remaining senses. Accordingly, the 
largest limbic input arose from the posterior cingulate area, where activity reflects the subjective salience of a stimulus, and which guides visual orienting (McCoy and Platt, 2005).

\section{Changes in auditory cortical projections}

Studies of auditory cortical modulation of SC neuron function have focused on the fAES. Deactivating fAES selectively abolishes multisensory integration in SC neurons while preserving unisensory responses (Jiang et al., 2001). Behaviorally, fAES deactivation induces significant impairment in auditory localization in the contralateral field (Malhotra et al., 2004; Malhotra and Lomber, 2007), a response that likely relies upon the output of these same SC neurons. Accordingly, fAES comprises the largest auditory cortical input to the SC in hearing cats and is the only field to make a substantial bilateral input (Butler et al., 2016b). Interestingly, the proportion of labeled cells in fAES is dramatically reduced following hearing loss, whereas proportions arising from other auditory areas are strengthened (Fig. 11). As a result, the total proportion of inputs to the SC arising from auditory cortex is slightly larger $(15.6 \%$ deaf vs $12.4 \%$ hearing), but less discriminate in the deaf brain. A dramatic decrease in the proportion of labeled cells in fAES was also observed in the hemisphere contralateral to tracer injection; whereas no labeled cells were observed in the current study, this field comprised $4.3 \%$ of total projections to the SC in normal hearing animals $(\sim 62 \%$ of all contralateral projections) (Butler et al., 2016b). We have argued previously that a bilateral auditory projection to the SC may reflect a necessity for bilateral auditory cues to guide orientation behavior; the absence of a contralateral projection from fAES following deafness supports this idea and may reflect the reorganized role of fAES in visual processing. The absence of a discrete corticotectal projection from fAES is significant because deactivation of this area significantly impairs visual localization in the deaf (Meredith et al., 2011). Because corticocortical connectivity to fAES is largely unchanged following hearing loss (Meredith et al., 2016), it is unlikely that this behavioral effect is mediated via indirect effects on corticotectally projecting areas to which fAES is connected. Rather, projections from fAES to other subcortical nuclei involved in orienting behavior, such as the striatum, may be retained to mediate this reorganization.

That a robust corticocollicular projection from fAES fails to develop in early-deafness fits well with previous hypotheses on corticotectal circuit development. Although little is known about the mechanism that underlies the development of multisensory

\section{DEAF}
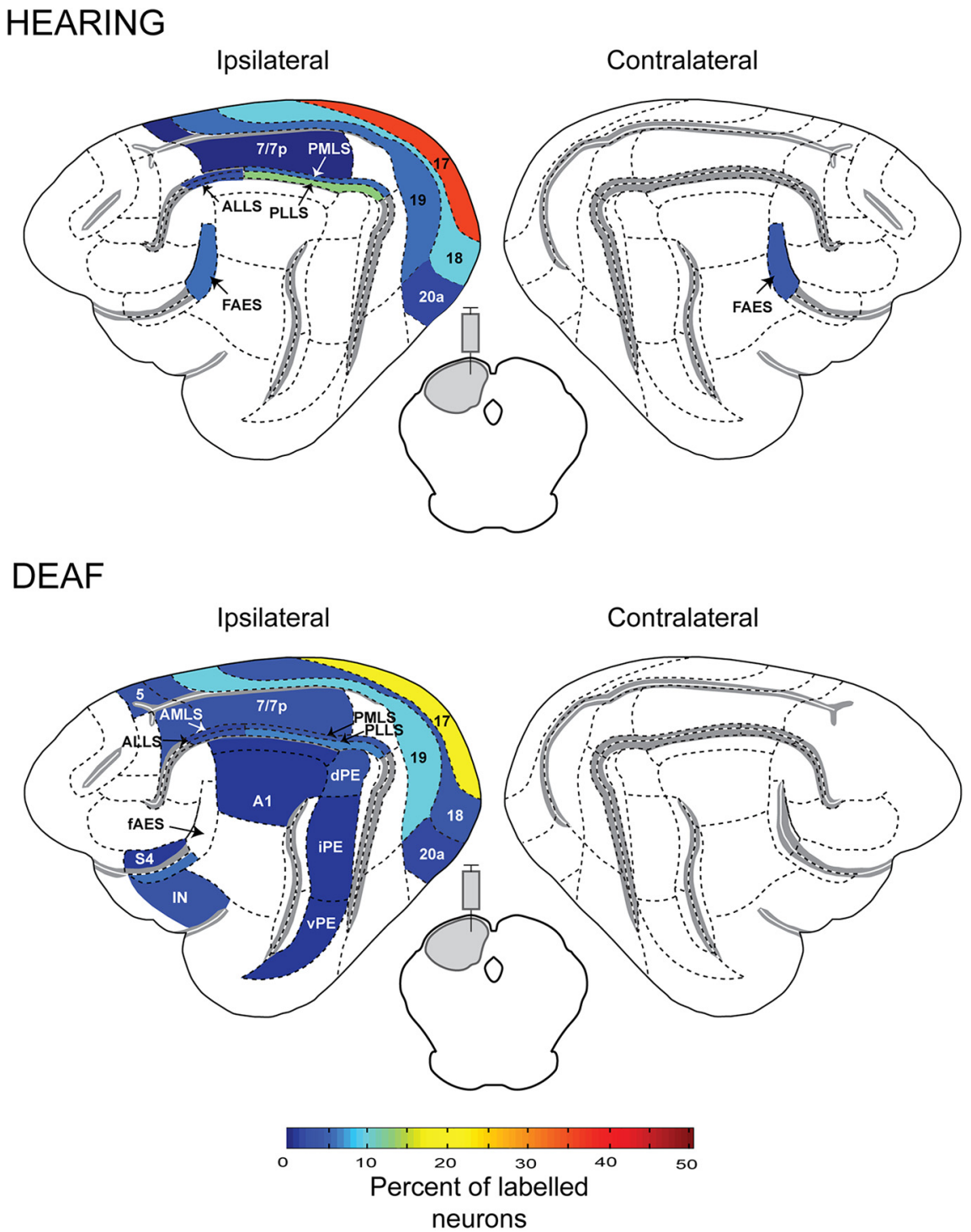

Figure 11. Summary of the cortical projections to the $\mathrm{SC}$ for the animals described in the current study (Deaf) and those previously described by Butler et al. (2016b) (Hearing). In each case, areas containing $>1 \%$ of the total labeled cells are shown, with projecting strength color coded according to the color bar at the bottom. In both groups, each of the visual areas involved in region with a direct connection, and this projection was observed bilaterally. In stark comparison, a diffuse pattern of connectivity spanning multiple auditory cortical regions was observed in deaf animals: A1, Primary auditory cortex; dPE, dorsal posterior ectosylvian gyrus; $i \mathrm{PE}$, intermediate posterior ectosylvian gyrus; $\mathrm{VPE}$, ventral posterior ectosylvian gyrus; $\mathrm{DZ}$, dorsal zone of auditory cortex; IN, insular auditory cortex. ALLS, Anterolateral lateral suprasylvian area; AMLS, anteromedial lateral suprasylvian area.

integration in the SC, one hypothesis that accounts for prolonged development of cortical influence involves a Hebbian mechanism, through which projections from sensory cortex to the SC are strengthened by coincident activation in an experiencedependent manner, whereas projections that do not provide coincident activity are pruned away. Such a mechanism has been modeled by Cuppini et al. (2011, 2012), who suggest that projections from sensory areas surrounding the anterior ectosylvian sulcus (AEV, fAES, S4) are present but weak at birth. According to the model, these projections are strengthened by Hebbian learning rules and develop receptive fields, which shrink and come into register, resulting in adult-like multisensory response properties. Furthermore, it predicts that, if this pattern of corticotectal projections fails to develop, due to an absence of appropriate cross-modal experience, the resulting cortical influence 
would be nonspecific and unable to support multisensory integration (Patton and Anastasio, 2003; Cuppini et al., 2010; Ohshiro et al., 2011). This has been functionally demonstrated in the visual system; although in normally developed animals, association cortex selectively enhances the response of target SC neurons to multisensory stimulus combinations likely to have arisen from a single event, corticotectal enhancement appears indiscriminate in animals raised in complete darkness ( $\mathrm{Yu}$ et al., 2013). Although functional consequences of early-deafness on SC modulation remain unknown, the current study provides anatomical evidence for a generalized loss of specificity in corticotectal projections, in favor of more diffuse connectivity. This diffusivity may reflect the absence of activity-dependent strengthening of the fAES projection, and reduced pruning of projections from other auditory cortical regions. There is also a great deal of evidence to support that functional reorganization of auditory cortex occurs following deafness. Thus, an increased proportion of labeled cells in auditory cortical fields outside of fAES may also reflect a strengthening of projections from these regions that is related to the flow of information from the replacement modality. Whether this modified pattern of connectivity gives rise to functionally indiscriminate modulation of SC activity, and whether reorganized auditory cortical inputs provide useful information regarding stimuli in the remaining sensory modalities warrants further investigation.

\section{Deafness differs from the dark}

Although there are commonalities between the functional consequences of dark rearing and anatomical consequences of early deafness, it is crucial to highlight a significant difference. While dark rearing renders the modulatory effect of AEV insufficient to support multisensory integration, Yu et al. (2013) demonstrated that the impact on target SC neurons is substantially greater than in animals raised in a normal visual environment. It is difficult to imagine how this pattern of results could arise subsequent to a loss of projections as dramatic as observed in fAES. This discrepancy may reflect an important physiological difference; dark rearing does not involve the degree of ganglion cell loss that occurs in ototoxic deafening. Increased spontaneous firing rate in the darkreared visual system may be sufficient to maintain projections from AEV, whereas residual activity in surviving spiral ganglia of the deafened cochlea is incapable of similar maintenance.

\section{Dispersed corticotectal projection in the deaf}

Following deafness, crossmodal function is often identified in brain regions that normally process sound (Lomber et al., 2001; Meredith et al., 2011). Significant changes in neural projections within and between sensory cortices were thought to underlie these functional changes. However, recent studies of thalamocortical and corticocortical connections instead reveal a profound resilience of cortical afferent patterns following deafness (Kok et al., 2014; Chabot et al., 2015; Wong et al., 2015; Meredith et al., 2016; Butler et al., 2017, 2018; Kok and Lomber, 2017). In stark contrast, the present study demonstrates significant changes in the pattern of efferent projections arising from auditory cortex following deafness (Fig. 11).

Many visual and auditory cortical regions that project to the SC in the mature, intact cat (Harting et al., 1992; Chabot et al., 2013; Butler et al., 2016b) also project to the SC of newborn kittens (Stein and Edwards, 1979; Cornwell et al., 1984; Henderson and Blakemore, 1986). However, these nascent projections only develop characteristic topographic and laminar organization observed in mature animals after weeks of sensory experi- ence (Bruce, 1993). Therefore, dispersion of cortical efferents to the SC following perinatal deafness is most likely an activitydependent modification of cortical projections.

The SC maintains sensory representations of the world to orient toward behaviorally relevant stimuli. Through normal development, SC neurons integrate converging inputs from sensory regions along the anterior ectosylvian sulcus (AEV, fAES, S4). These converging inputs elicit a response from SC neurons exceeding that elicited by any modality in isolation, increasing the likelihood that a stimulus engaging multiple senses will be accurately detected. The experience-dependent development of this top-down modulation is prolonged and is thus highly susceptible to impoverished input. The current study demonstrates that, following early deafness, the normal pattern of auditory corticotectal projections is replaced by a more diffuse pattern. In addition, there is an increase in the proportion of projections to the SC that originate in limbic cortical areas, possibly reflecting a larger influence of learned stimulus-associations on behavior. Together, these results provide the first anatomical evidence of altered auditory cortical outputs following sensory loss.

\section{References}

Alvarado JC, Stanford TR, Rowland BA, Vaughan JW, Stein BE (2009) Multisensory integration in the superior colliculus requires synergy among corticocollicular inputs. J Neurosci 29:6580-6592. CrossRef Medline

Baleydier C, Kahungu M, Mauguiere F (1983) A crossed corticotectal projection from the lateral suprasylvian area in the cat. J Comp Neurol 214: 344-351. CrossRef Medline

Benedek G, Mucke L, Norita M, Albowitz B, Creutzfeldt OD (1988) Alterior ectosylvian visual area (AEV) of the cat: physiological properties. Prog Brain Res 75:245-255. CrossRef Medline

Bruce LL (1993) Postnatal development and specification of the cat's visual corticotectal projection: efferents from the posteromedial lateral suprasylvian area. Brain Red Dev Brain Res 21:47-61. Medline

Butler BE, Chabot N, Lomber SG (2016a) Quantifying and comparing the pattern of thalamic and cortical projections to the posterior auditory field in hearing and deaf cats. J Comp Neurol 524:3042-3063. CrossRef Medline

Butler BE, Chabot N, Lomber SG (2016b) A quantitative comparison of the hemispheric, area, and laminar origins of sensory and motor cortical projections to the superior colliculus of the cat. J Comp Neurol 524:26232642. CrossRef Medline

Butler BE, Chabot N, Kral A, Lomber SG (2017) Origins of thalamic and cortical projections to the posterior auditory field in congenitally deaf cats. Hear Res 343:118-127. CrossRef Medline

Butler BE, de la Rua A, Ward-Able T, Lomber SG (2018) Cortical and thalamic connectivity to the second auditory cortex of the cat is resilient to the onset of deafness. Brain Struct Funct 223:819-835. CrossRef Medline

Chabot N, Mellott JG, Hall AJ, Tichenoff EL, Lomber SG (2013) Cerebral origins of the auditory projection to the superior colliculus of the cat. Hear Res 300:33-45. CrossRef Medline

Chabot N, Butler BE, Lomber SG (2015) Differential modification of cortical and thalamic projections to cat primary auditory cortex following early- and late-onset deafness. J Comp Neurol 523:2297-2320. CrossRef Medline

Clarey JC, Irvine DR (1986) Auditory response properties of neurons in the anterior ectosylvian sulcus of the cat. Brain Res 386:12-19. CrossRef Medline

Clascá F, Llamas A, Reinoso-Suárez F (1997) Insular cortex and neighboring fields in the cat: a redefinition based on cortical microarchitecture and connections with the thalamus. J Comp Neurol 384:456-482. CrossRef Medline

Clemo HR, Stein BE (1982) Somatosensory cortex: a 'new' somatotopic representation. Brain Res 235:162-168. CrossRef Medline

Clemo HR, Stein BE (1983) Organization of a fourth somatosensory area of cortex in cat. J Neurophysiol 50:910-925. CrossRef Medline

Cornwell P, Ravizza R, Payne B (1984) Extrinsic visual and auditory cortical connections in the 4-day-old kitten. J Comp Neurol 10:97-120. CrossRef Medline

Cuppini C, Ursino M, Magosso E, Rowland BA, Stein BE (2010) An emergent model of multisensory integration in superior colliculus neurons. Front Integr Neurosci 4:6. CrossRef Medline 
Cuppini C, Stein BE, Rowland BA, Magosso E, Ursino M (2011) A computational study of multisensory maturation in the superior colliculus. Exp Brain Res 213:341-349. CrossRef Medline

Cuppini C, Magosso E, Rowland B, Stein B, Ursino M (2012) Hebbian mechanisms help explain development of multisensory integration in the superior colliculus: a neural network model. Biol Cybern 106:691-713. CrossRef Medline

Harting JK, Updyke BV, Van Lieshout DP (1992) Corticotectal projections in the cat, anterograde transport studies of 25 cortical areas. J Comp Neurol 324:379-414. CrossRef Medline

Henderson Z, Blakemore C (1986) Organization of the visual pathways in the newborn kitten. Neurosci Res 3:628-659. CrossRef Medline

Jiang H, Lepore F, Ptito M, Guillemot JP (1994) Sensory modality distribution in the anterior ectosylvian cortex (AEC) of cats. Exp Brain Res 97: 404-414. Medline

Jiang W, Wallace MT, Jiang H, Vaughan JW, Stein BE (2001) Two cortical areas mediate multisensory integration in superior colliculus neurons. J Neurophysiol 85:506-522. CrossRef Medline

Kawamura S, Sprague JM, Niimi K (1974) Corticofugal projections from the visual cortices to the thalamus, pretectum and superior colliculus in the cat. J Comp Neurol 158:339-362. CrossRef Medline

Kok MA, Lomber SG (2017) Origin of the thalamic projection to dorsal auditory cortex in hearing and deafness. Hear Res 343:108-117. CrossRef Medline

Kok MA, Chabot N, Lomber SG (2014) Cross-modal reorganization of cortical afferents to dorsal auditory cortex following early- and late-onset deafness. J Comp Neurol 522:654-675. CrossRef Medline

Lomber SG, Payne BR, Cornwell P (2001) Role of the superior colliculus in analyses of space: superficial and intermediate layer contributions to visual orienting, auditory orienting, and visuospatial discriminations during unilateral and bilateral deactivations. J Comp Neurol 441:44-57. CrossRef Medline

Malhotra S, Lomber SG (2007) Sound localization during homotopic and heterotopic bilateral cooling deactivation of primary and nonprimary auditory cortical areas in the cat. J Neurophysiol 97:26-43. CrossRef Medline

Malhotra S, Hall AJ, Lomber SG (2004) Cortical control of sound localization in the cat: unilateral cooling deactivation of 19 cerebral areas. J Neurophysiol 92:1625-1643. CrossRef Medline

McCoy AN, Platt ML (2005) Risk-sensitive neurons in macaque posterior cingulate cortex. Nat Neurosci 8:1220-1227. CrossRef Medline

Mellott JG, Van der Gucht E, Lee CC, Carrasco A, Winer JA, Lomber SG (2010) Areas of the cat auditory cortex as defined by neurofilament proteins expressing SMI-32. Hear Res 267:119-136. CrossRef Medline

Meredith MA, Clemo HR (1989) Auditory cortical projection from the anterior ectosylvian sulcus (Field AES) to the superior colliculus in the cat: an anatomical and electrophysiological study. J Comp Neurol 289:687707. CrossRef Medline

Meredith MA, Kryklywy J, McMillan AJ, Malhotra S, Lum-Tai R, Lomber SG (2011) Crossmodal reorganization in the early deaf switches sensory, but not behavioral roles of auditory cortex. Proc Natl Acad Sci U S A 108: 8856-8861. CrossRef Medline

Meredith MA, Clemo HR, Corley SB, Chabot N, Lomber SG (2016) Cortical and thalamic connectivity of the auditory anterior ectosylvian cortex of early-deaf cats: implications for neural mechanisms of crossmodal plasticity. Hear Res 333:25-36. CrossRef Medline

Morgan ML, DeAngelis GC, Angelaki DE (2008) Multisensory integration in macaque visual cortex depends on cue reliability. Neuron 59:662-673. CrossRef Medline

Olson CR, Graybiel AM (1987) Ectosylvian visual area of the cat: location, retinotopic organization, and connections. J Comp Neurol 261:277-294. CrossRef Medline
Ohshiro T, Angelaki DE, DeAngelis GC (2011) A normalization model of multisensory integration. Nat Neurosci 14:775-782. CrossRef Medline

Patton PE, Anastasio TJ (2003) Modeling crossmodal enhancement and modality-specific suppression in multisensory neurons. Neural Comput 15:783-810. CrossRef Medline

Payne BR, Lomber SG (1996) Age dependent modification of cytochrome oxidase activity in the cat dorsal lateral geniculate nucleus following removal of primary visual cortex. Vis Neurosci 13:805-816. CrossRef Medline

Shipley C, Buchwald JS, Norman R, Guthrie D (1980) Brain stem auditory evoked response development in the kitten. Brain Res 182:313-326. CrossRef Medline

Stein BE (1984) Development of the superior colliculus. Annu Rev Neurosci 7:95-125. CrossRef Medline

Stein BE, ed (2012) The new handbook of multisensory processing. Cambridge, MA: Massachusetts Institute of Technology.

Stein BE, Edwards SB (1979) Corticotectal and other corticofugal projections in neonatal cat. Brain Res 161:399-409. CrossRef Medline

Stein BE, Meredith MA, Huneycutt WS, McDade L (1989) Behavioral indices of multisensory integration: orientation to visual cues is affected by auditory stimuli. J Cogn Neurosci 1:12-24. CrossRef Medline

Tusa RJ, Palmer LA, Rosenquist AC (1981) Multiple cortical visual areas. In: Cortical sensory organization, Vol 2: Multiple visual areas (Woolsey CN, ed), pp 1-31. New York, NY: Humana.

van der Gucht E, Vandesande F, Arckens L (2001) Neurofilament protein: a selective marker for the architectonic parcellation of the visual cortex in adult cat brain. J Comp Neurol 441:345-368. CrossRef Medline

Veenman CL, Reiner A, Honig MG (1992) Biotinylated dextran amine as an anterograde tracer for single- and double-labeling studies. J Neurosci Methods 41:239-254. CrossRef Medline

Wallace MT, Stein BE (2001) Sensory and multisensory responses in the newborn monkey superior colliculus. J Neurosci 21:8886-8894. Medline

Wallace MT, Meredith MA, Stein BE (1993) Converging influences from visual, auditory, and somatosensory cortices onto output neurons of the superior colliculus. J Neurophys 69:1797-1809. CrossRef Medline

Wallace MT, Ramachandran R, Stein BE (2004) A revised view of sensory cortical parcellation. Proc Natl Acad Sci U S A 101:2167-2172. CrossRef Medline

Wong C, Chabot N, Kok MA, Lomber SG (2014) Modified areal cartography in auditory cortex following early- and late-onset deafness. Cereb Cortex 24:1778-1792. CrossRef Medline

Wong C, Chabot N, Kok MA, Lomber SG (2015) Amplified somatosensory and visual cortical projections to a core auditory area, the anterior auditory field, following early- and late-onset deafness. J Comp Neurol 523: 1925-1947. CrossRef Medline

Xu J, Yu L, Stanford TR, Rowland BA, Stein BE (2011) Rearing animals in omnidirectional sound disrupts the maturation of multisensory integration in superior colliculus neurons. Program No.481.05/LL21 Neuroscience Meeting Planner. Washington DC: Society for Neuroscience.

Xu J, Yu L, Rowland BA, Stanford TR, Stein BE (2012) Incorporating crossmodal statistics in the development and maintenance of multisensory integration. J Neurosci 32:2287-2298. CrossRef Medline

Xu SA, Shepherd RK, Chen Y, Clark GM (1993) Profound hearing loss in the cat following the single co-administration of kanamycin and ethacrynic acid. Hear Res 70:205-215. CrossRef Medline

Yu L, Rowland BA, Stein BE (2010) Initiating the development of multisensory integration by manipulating sensory experience. J Neurosci 30: 4904-4913. CrossRef Medline

Yu L, Xu J, Rowland BA, Stein BE (2013) Development of cortical influences on superior colliculus multisensory neurons: effects of dark-rearing. Eur J Neurosci 37:1594-1601. CrossRef Medline 